\title{
POSSIBILIDADES DO DESENHO À MÃO NA ETNOGRAFIA URBANA: ESTUDO DE CASO EM FLORIANÓPOLIS/SC
}

\author{
Guilherme Ruchaud ${ }^{1}$ \\ Louise Prado Alfonso ${ }^{2}$
}

\section{Introdução}

O Monte Serrat, comunidade localizada no Maciço do Morro da Cruz, área central de Florianópolis/SC, foi onde fiz um intenso trabalho de campo que perpassou meu Trabalho de Conclusão de Curso em Arquitetura e Urbanismo (2015) e meu mestrado em Antropologia (2017-19). Ao longo de todo esse trabalho, o desenho me acompanhou desempenhando diversos papéis, que de alguma maneira se expressam na própria materialidade do traço.

Entre os objetivos dessa inserção em campo em uma comunidade histórica, negra e periférica da cidade estava a busca por apreender aspectos de sua realidade que só uma longa e paciente estadia em campo pode revelar - principalmente a pessoas brancas de classe média que têm sido submetidas a representações e narrativas que, historicamente, deslegitimam a própria existência de territórios como o Monte Serrat. Entre as ferramentas dessa permanência, além das muitas e intensas interlocuções, está o olhar para a materialidade que, interpretada sob a ótica de metodologias apropriadas, pode ser reveladora de dinâmicas sociais tanto do interior da comunidade como da relação entre a comunidade e a cidade. A própria impermanência dessa materialidade - alguns dos desenhos que compõem este ensaio exibem lugares que já não existem na configuração como foram retratados - expressa a cidade não como uma obra acabada, mas como um objeto em permanente construção coletiva, o "fazer-cidade" de que nos fala Michel Agier, para quem "a cidade é feita essencialmente de movimento" (2015, p. 484).

\footnotetext{
${ }^{1}$ Universidade Federal de Santa Catarina, Brasil. Email: guiruchaud@gmail.com ORCID id: https://orcid.org/0000-0001-8602-326X

${ }^{2}$ Universidade Federal de Pelotas, Brasil. Email: louiseturismo@yahoo.com.br ORCID id: https://orcid.org/0000-0001-8602-326X
} 
O ensaio que acompanha estas reflexões está disposto em ordem cronológica, por uma escolha metodológica que, espero, será entendida ao longo da leitura.

\section{Desenho de observação}

É possível observar um primeiro e importante papel desempenhado pelo desenho nesse trabalho, já que a prática do desenho de observação requer um olhar atento a detalhes que poderiam ser ignorados de outra maneira. Nesse sentido é que pela primeira vez o desenho de observação se intrometeu em minha pesquisa, normalmente sendo desenvolvido em momentos de espera por interlocutoras/es ou mesmo em incursões de observação flutuante (Pétonnet, 2008) desenvolvidas pelas ruas do Monte Serrat. Os seis primeiros desenhos que compõem este ensaio foram feitos nesse contexto, normalmente desenvolvidos em poucos minutos, com a finalidade própria da apreensão da forma. 


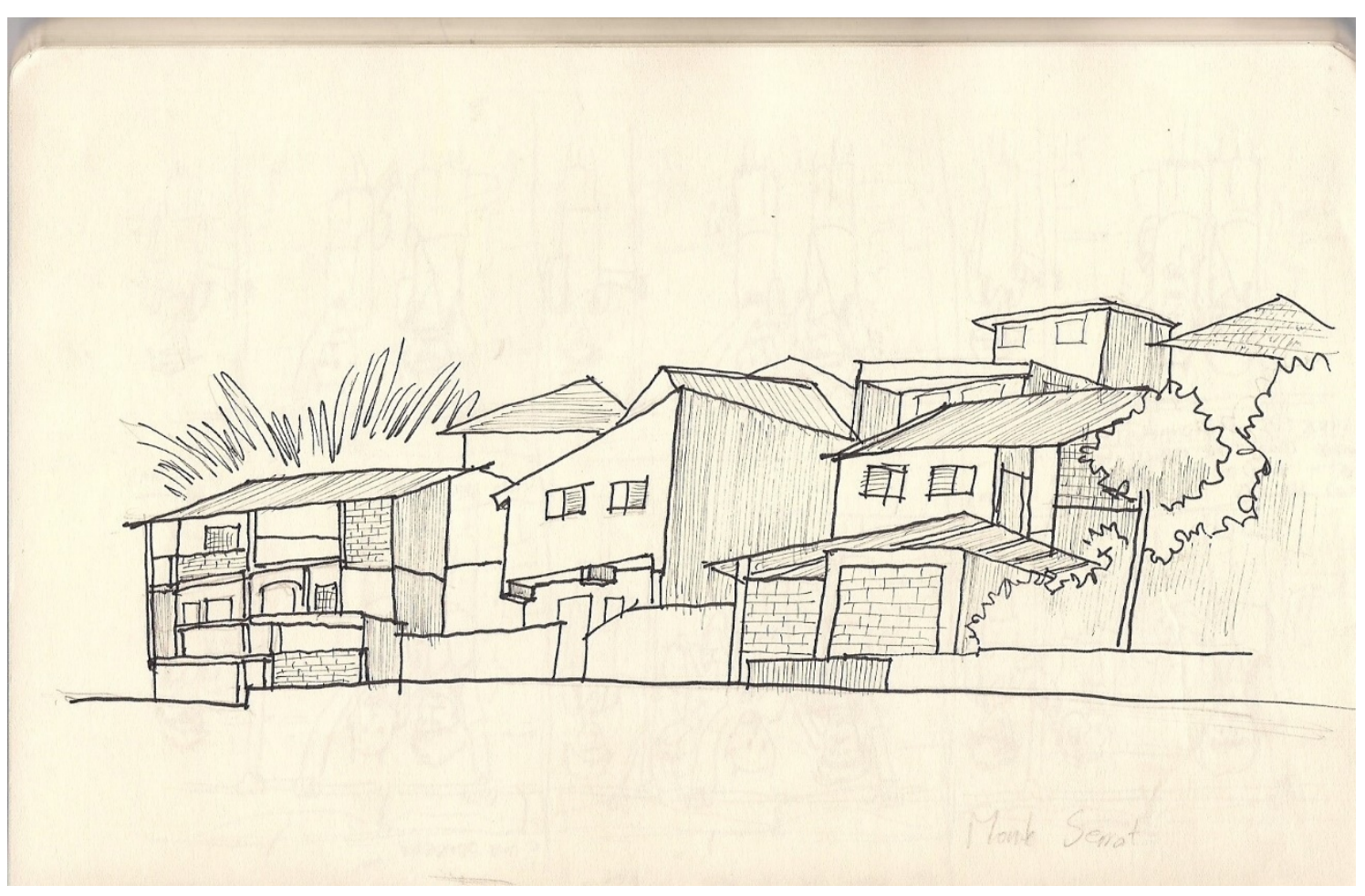

Desenho 1 - Casas do Monte Serrat, 2015.

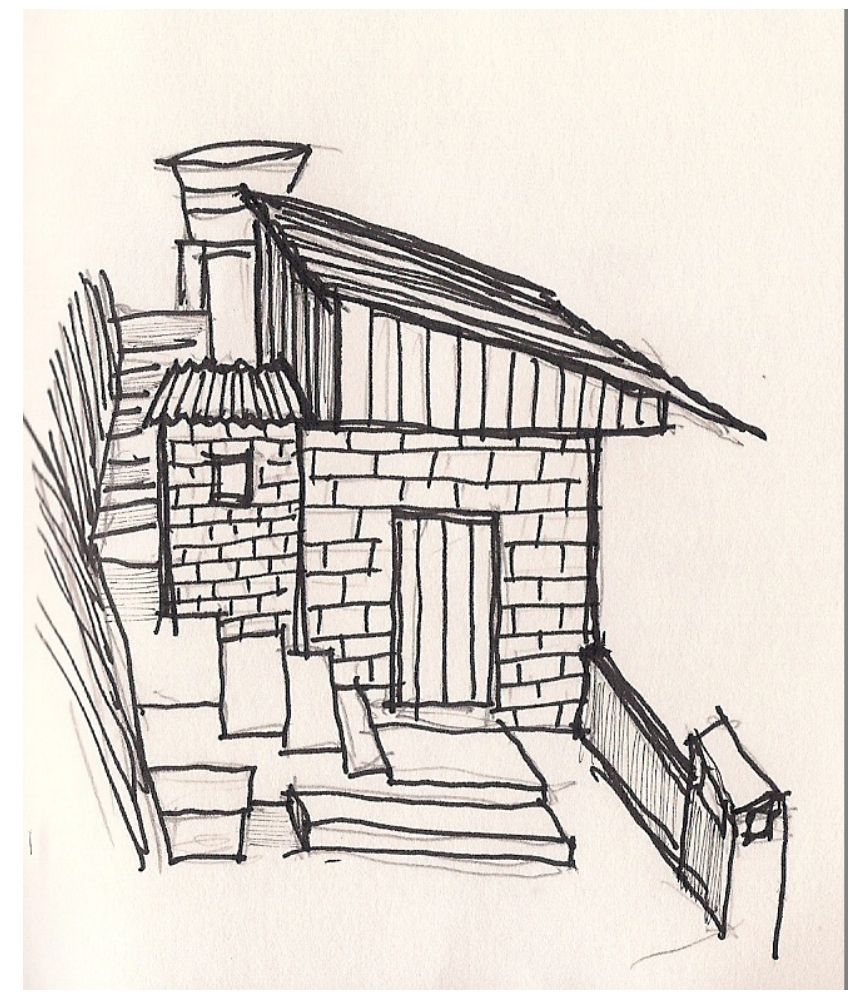

Desenho 2 - Casa do Alto da Caieira, comunidade vizinha ao Monte Serrat, 2015. 


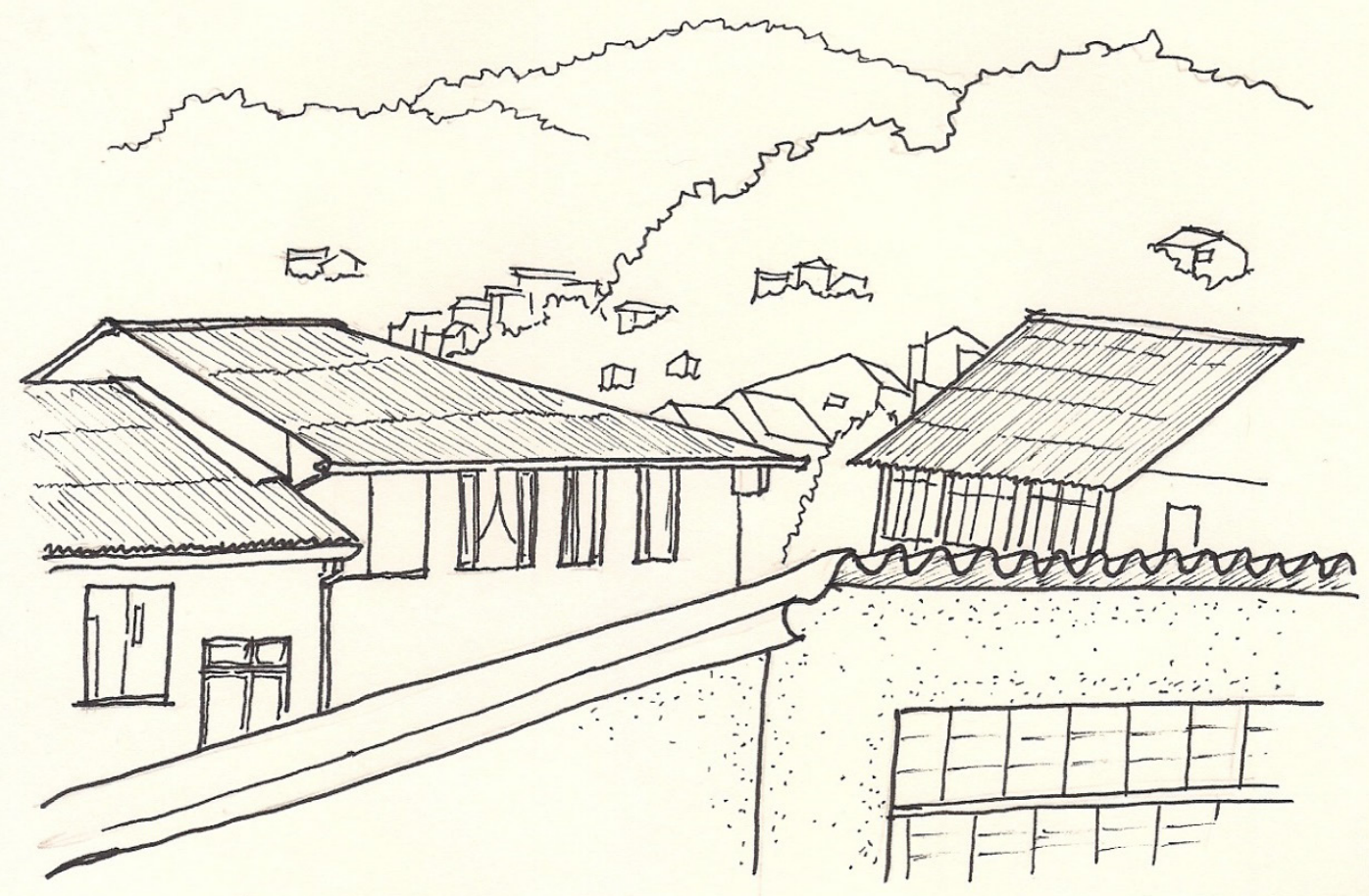

Desenho 3 - Casas do Monte Serrat vistas pela janela da sede da SRCS Embaixada Copa Lord, janeiro de 2018.

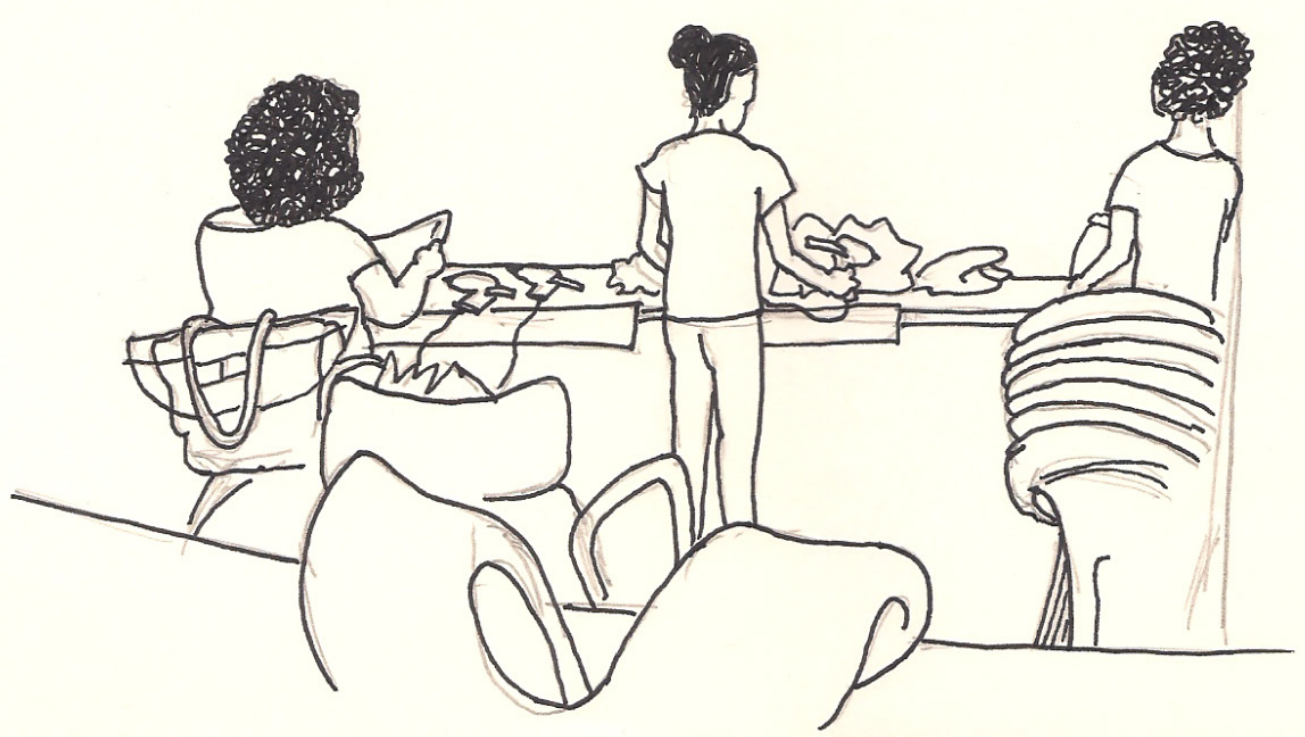

Desenho 4 - Rotina de trabalho na sede da SRCS Embaixada Copa Lord, janeiro de 2018. 


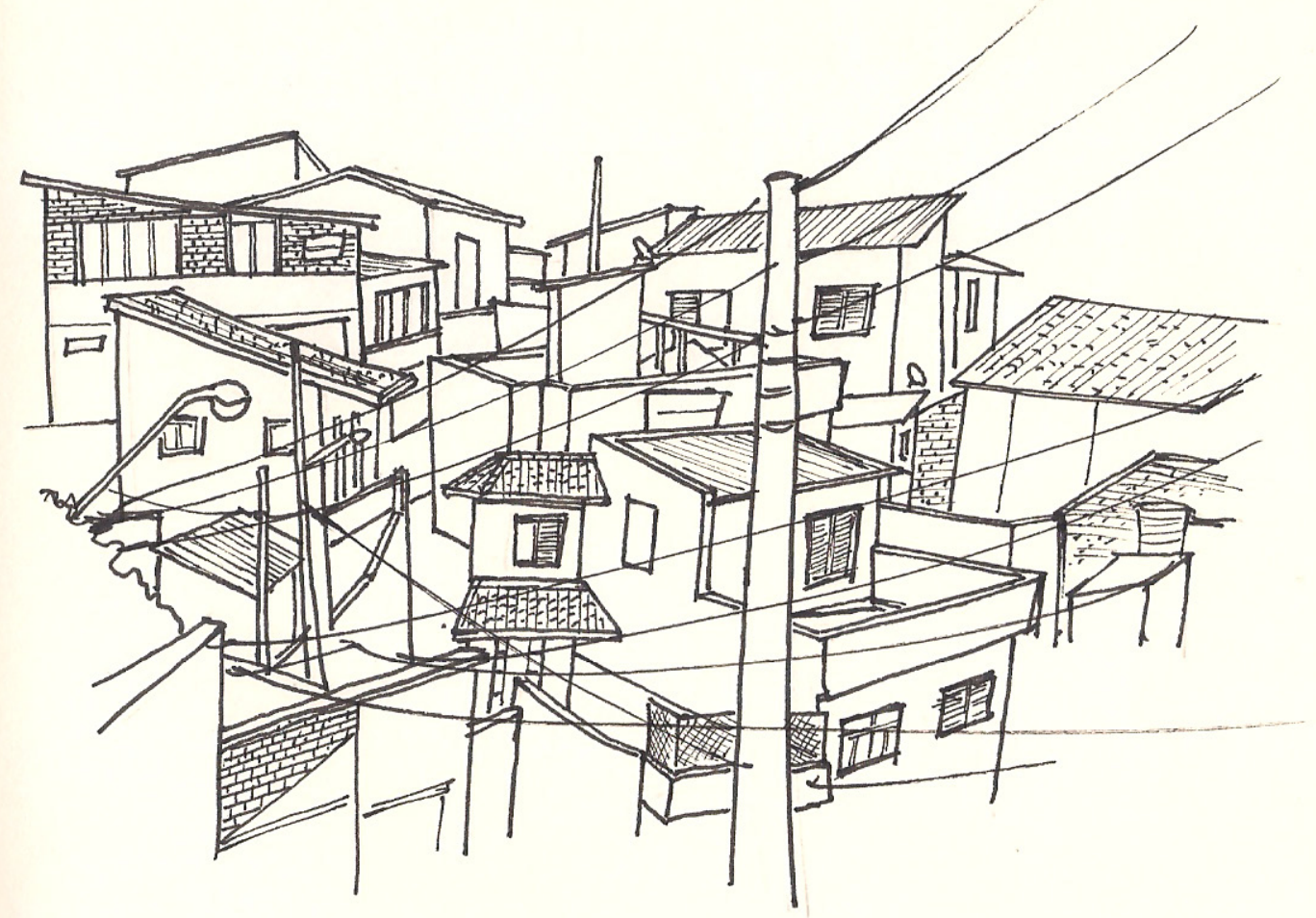

Desenho 5 - Casas do Monte Serrat, desenhadas à noite após uma festa na sede da SRCS Copa Lord, 2018.

Esse processo trouxe consigo o aprendizado, discutido por Karina Kuschnir (2016) e Aina Azevedo (2016), de que o desenho não tem como finalidade o retrato fiel de uma realidade que está posta, mas sim uma interpretação, uma narrativa produzida pela pessoa que o desenvolve, condicionada não somente pela realidade objetiva da materialidade, mas pelas subjetividades da/o autor/a e por circunstâncias intangíveis do momento em que se desenvolve o gesto do desenho. Nesse sentido, cada um desses desenhos de observação é por si só parte de um longo processo de interpretação da realidade que compõe o trabalho de etnografia. O gesto do desenho pressupõe o estabelecimento de uma relação muito específica com o território, em que uma permanência mais ou menos prolongada e atenta propicia a apreensão, além da forma que se busca interpretar, de sons, cheiros, variações climáticas e presenças outras que nos rodeiam (Ingold, 2013). Nessa mesma medida é que 
o desenho de observação pode mesmo trazer novas respostas e novas questões de pesquisa, não só durante o gesto em si, mas em uma interpretação feita posteriormente sobre as escolhas que o guiaram.

\section{Maturação e reflexão}

Em um segundo momento da pesquisa, um processo de reflexão em parceria com minha orientadora desvendou novas potencialidades para o desenho como forma de expressão e narrativa. A fotografia amadora, sempre com uso de um aparelho celular, já vinha compondo parte relevante do trabalho, sempre com a necessidade de situar as escolhas e seleções feitas no gesto do 'clique'. No entanto, assim como o desenho, a fotografia encontra limitações metodológicas, essas associadas a momentos em que pode ser eventualmente inapropriado sacar o celular para fotografar, seja pela própria dinâmica de interlocução que se está desenvolvendo, seja por dinâmicas culturais locais. Nessas situações o desenho se revelou uma rica possiblidade de retrato feito a posteriori, situação que reforça a necessidade de reflexões sobre escolhas e perspectivas adotadas em cada narrativa gráfica. É o caso dos desenhos de 6 a 11 deste ensaio, onde busquei demonstrar situações de campo nas quais não se pôde fotografar.

É notável que, no caso do desenho desenvolvido no contexto de uma etnografia, acompanhando a construção do conhecimento antropológico, o resultado final tem pouca relevância do ponto de vista artístico, mas muita sob uma perspectiva de interpretação, revisita ao campo e construção de narrativas. Como nos lembra Azevedo (2016, p. 201), "um convite ao desenho na antropologia se compromete menos com o resultado final do que com o processo de desenhar como uma forma de pensar, observar e conhecer." $\mathrm{O}$ resultado final, nesse caso, ganha uma importância complementar à do próprio gesto, podendo nos dizer algo sobre nossa perspectiva em diferentes momentos e sobre as seleções do próprio olhar.

Uma breve comparação entre os primeiros desenhos (1-5) deste ensaio com os que os sucederam (6-11) revela uma transformação do olhar ao longo da pesquisa, em que a preocupação com a arte-finalização, que compõe paisagens mais ou menos estáticas, vai aos poucos dando lugar a linhas mais dinâmicas, cuja expressividade tende a redirecionar seu foco dos detalhes construtivos para relações mais amplas de escala e de ordenamento territorial, por exemplo. Ainda a esse respeito foi possível perceber um crescente 'povoamento' do desenho frente às paisagens aparentemente desertas, narradas nos 
primeiros momentos. Assim, entendo que essa transformação evidencia um processo de maturação e reflexão sobre as potencialidades metodológicas do desenho como parte do processo etnográfico; e, mais, uma ampliação do olhar do arquiteto para um olhar antropológico propiciado pela prática etnográfica. Em todos os casos, é sempre necessário observar que o desenho integra o trabalho etnográfico na medida em que se trata de um gesto de interpretação de uma realidade sempre sujeita às subjetividades de quem escreve, de modo a compor narrativas que nunca serão um pretenso retrato objetivo de uma realidade colocada.
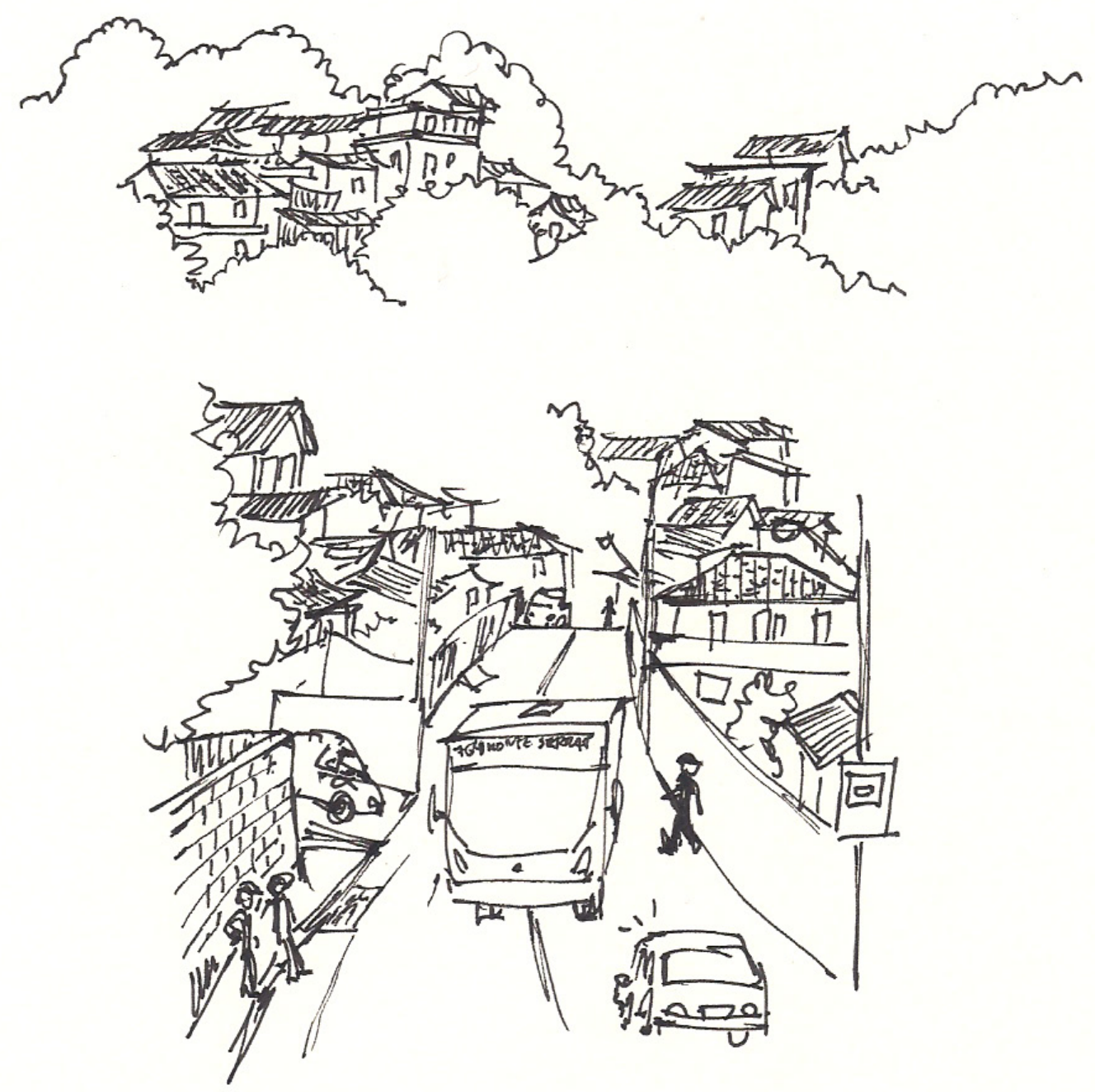

Desenho 6 - Paisagem do Monte Serrat vista do alto do morro, 2019. 


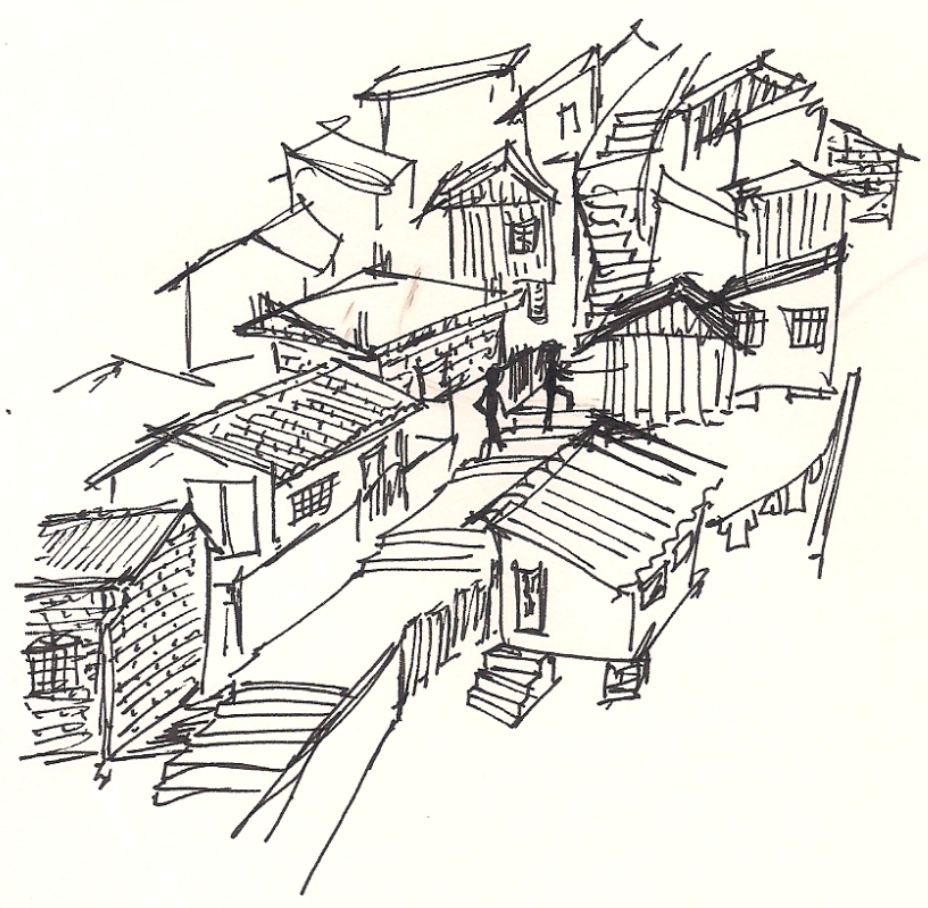

Desenho 7 - Subida da Servidão Nova Descoberta, no Monte Serrat, desenhado horas depois da visita, 2019.

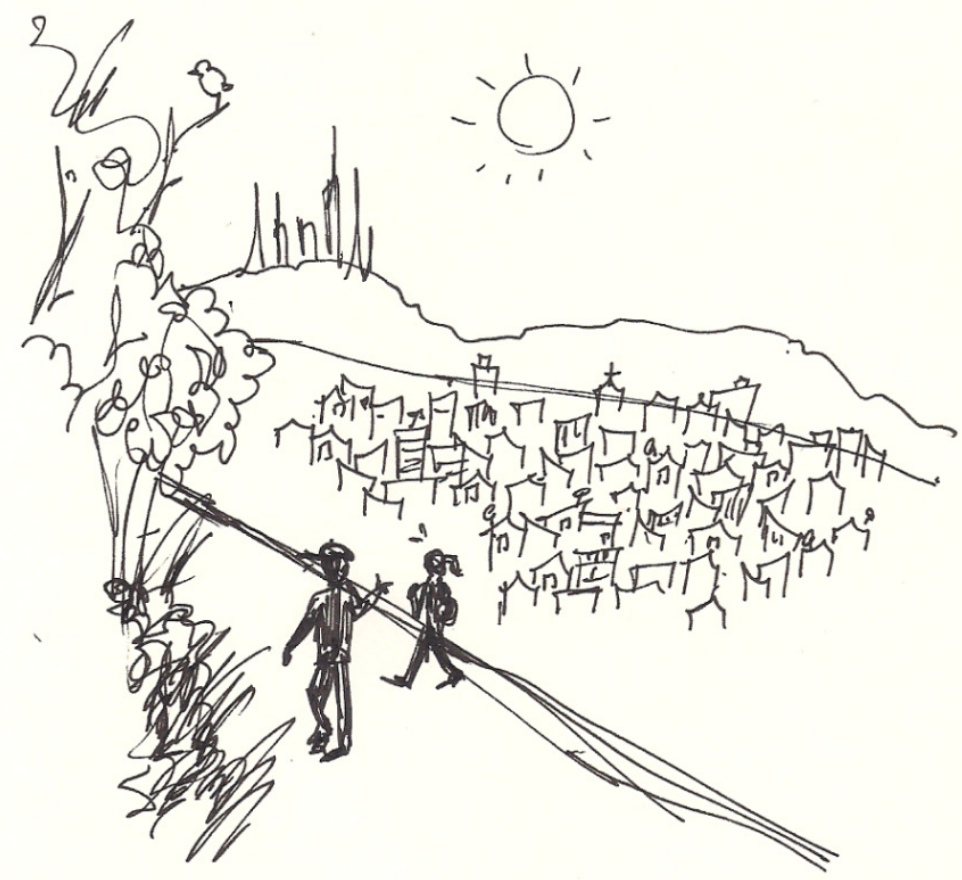

Desenho 8 - Comunidade do Alto do Caieira vista do Monte Serrat, desenhada horas depois da visita, 2019. 


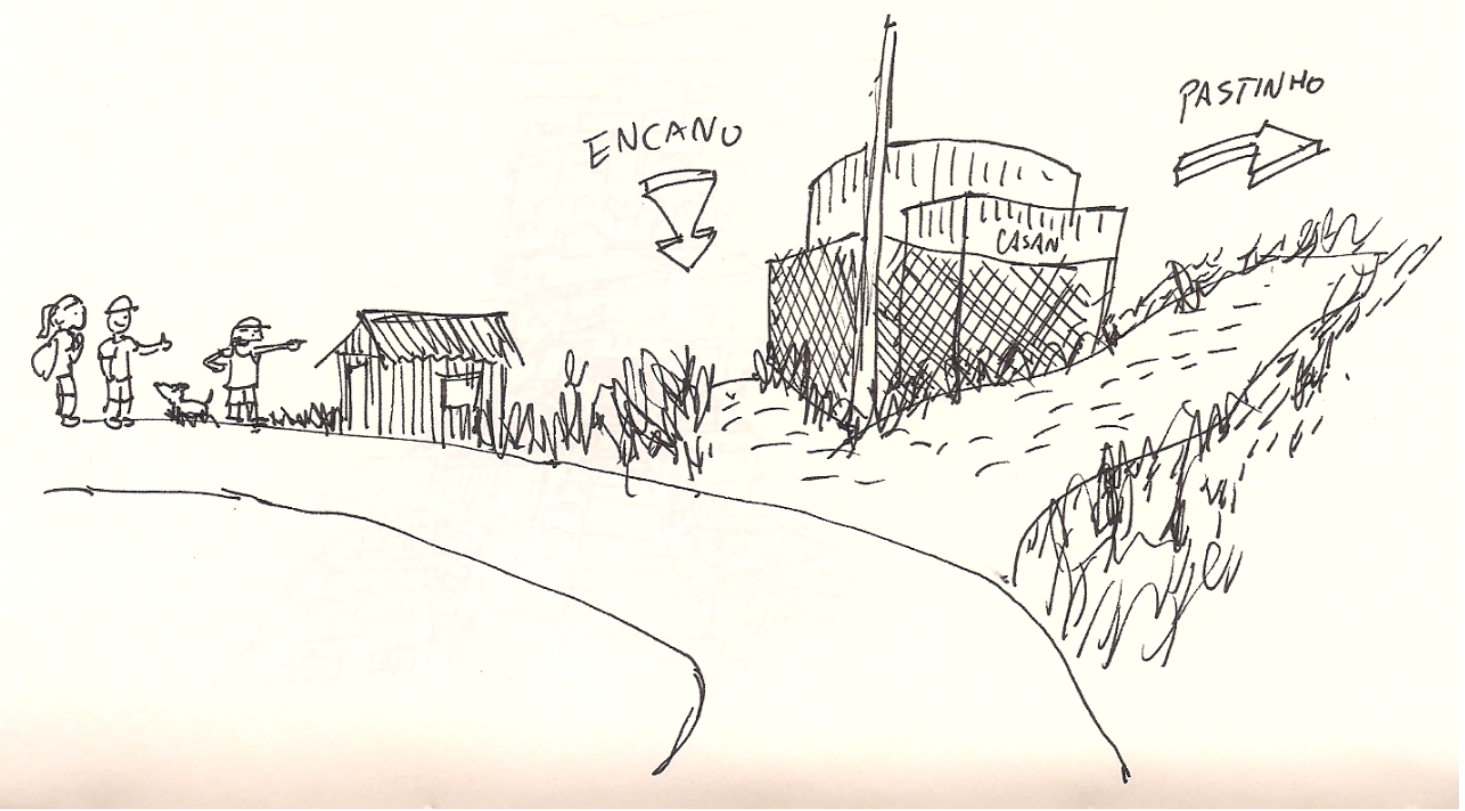

Desenho 9 - Interlocutor dando informações de localização no alto do Monte Serrat, desenho feito horas após a visita, 2019.

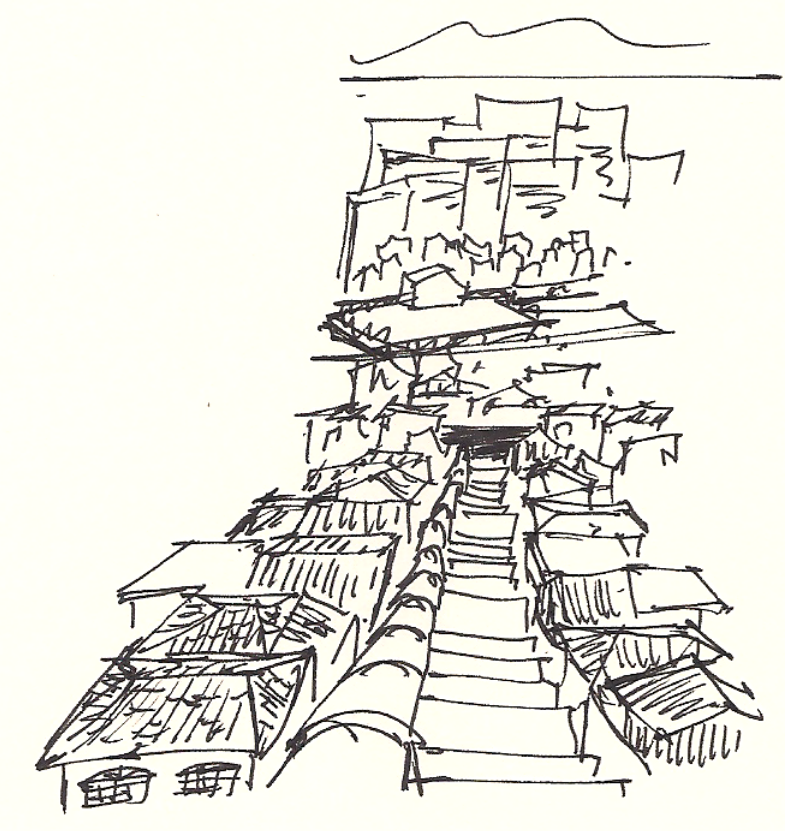

Desenho 10 - Monte Serrat e Centro da cidade vistos do alto da Servidão do Encano, desenhado horas depois da visita, 2019. 


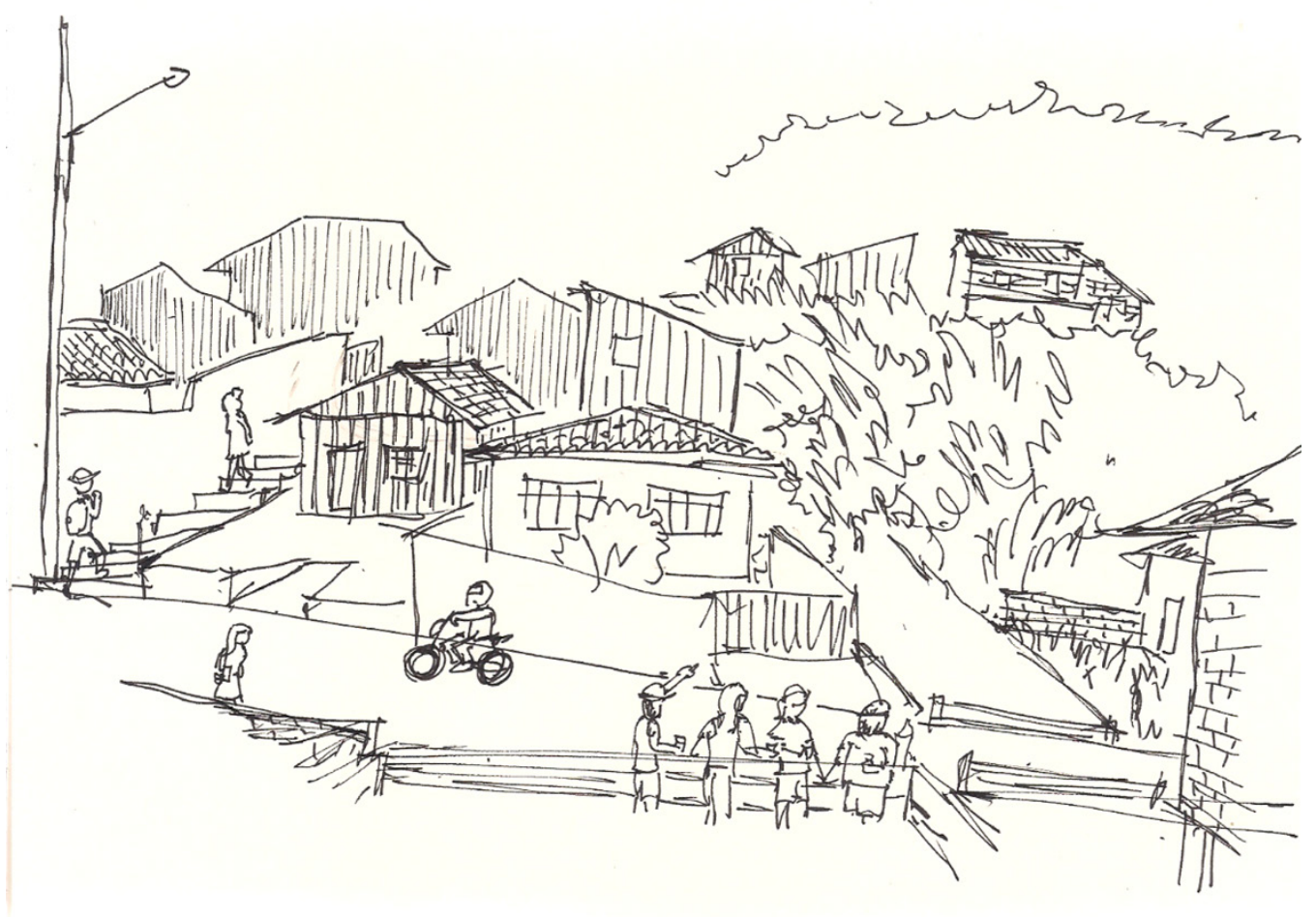

Desenho 11 - Situação de campo em um bar à beira da rua principal do Monte Serrat, feito no dia seguinte ao evento, 2019.

\section{Cartografia}

Em um momento tardio da pesquisa, o desenho voltou a se apresentar com novas possibilidades, ainda distintas daquelas discutidas até aqui, com potencialidades então impensadas. Um trabalho desenvolvido meses antes para uma disciplina do mestrado acabou se revelando como um potencial gesto de restituição acadêmica, que integra o próprio processo de produção de sentido da etnografia. O desafio de compor uma cartografia sensível do campo trabalhado me levou a elaborar um desenho com uma linguagem bastante distinta, repleta de seleções, feitas a partir dessa inserção em campo, com a pretensão de representar uma totalidade do território estudado, com ênfase para seus elementos considerados mais estruturadores. Esse desenho, desenvolvido à mão com auxílio de fotografias, e depois trabalhado digitalmente, em oposição aos demais, se tornou a base de uma cartografia digital interativa. Nesta, narrativas de pessoas diversas sobre a comunidade poderiam ser acessadas a partir das localidades representadas graficamente. Meses após a disciplina ter sido concluída, já no fim do mestrado, esse trabalho foi retomado e teve continuidade em parceria com o Conselho Comunitário e 
com a escola situada no morro, estendendo-se para além da defesa da dissertação. É desse trabalho que se trata o último desenho deste ensaio.

Essa cartografia interativa, representada aqui sob a forma do desenho base, reforçou o potencial de construção de narrativas do desenho, por se tratar de um conjunto de escolhas de elementos constitutivos do território da comunidade. Esses elementos constitutivos foram compreendidos ao longo da inserção em campo, e representam lugares que são centrais para a população do Monte Serrat em seu cotidiano. Também são referenciais da identidade da comunidade perante a cidade. Em coerência com o que viemos discutindo aqui, a cartografia não propõe um retrato acabado de um lugar estático, mas uma interpretação de vivências e narrativas do que é o Monte Serrat em relação com a cidade em um dado momento.

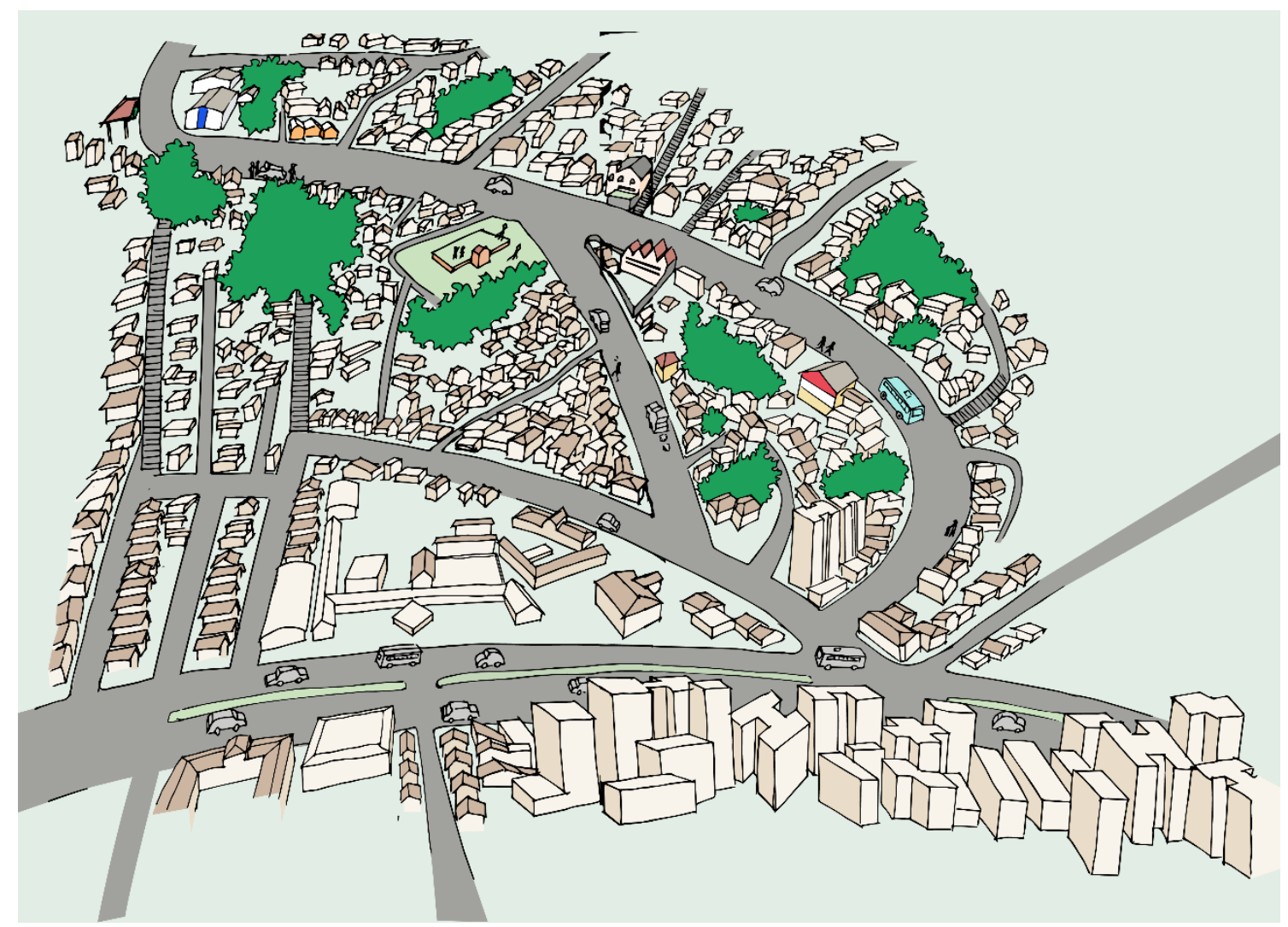

Desenho 12 - Cartografia do Monte Serrat, 2018.

\section{Considerações finais}

Ao longo do trabalho etnográfico é que as potencialidades do desenho como parte do processo de produção de sentido foram se revelando, tanto mais quanto se praticava o 
desenho de forma refletida. Em um primeiro momento essa reflexão se deu na medida em que o desenho de observação propiciava uma forma de aguçar o olhar para a materialidade; mas não custei a perceber que outros tantos sentidos podem ser trabalhados a partir da permanência atenta e dedicada necessária a esse gesto. Outras potencialidades foram sendo reveladas conforme se refletia sobre o desenho como mais uma forma de interpretação e construção de narrativas sobre o território que eu estava estudando. Assim, com o desenho ocorre como com a escrita acadêmica, em que revisões bibliográficas, Interlocuções e vivências de campo se complementam, inevitavelmente, com as subjetividades trazidas pela própria biografia de quem escreve e por condicionantes únicas, ao momento em que se desenvolve a pesquisa. Novamente convido Kuschnir (2016, p. 9) a compartilhar suas reflexões a respeito:

\footnotetext{
É do reconhecimento desse self, e não somente daquilo que está fora dele, que o investigador vivencia (e registra) o mundo à sua volta. Ou seja, o sentido de um desenho é indissociável da biografia, do olhar e da imaginação de seu autor, bem como das condições em que foi produzido, tema central na discussão contemporânea sobre a autoria etnográfica. (...) o que está em jogo não é tanto o resultado - a linha desenhada - mas o processo vivido: aquilo que o desenhador passa a enxergar e conhecer a partir da experiência de traçar o papel. O tempo é alongado pela imersão do observador numa relação com quem (ou o quê) observa.
}

Assim, o desenho aqui aparece não como uma ferramenta de representação e expressão embora também possua esses atributos - mas como um modo de pensar, de estabelecer relações e compor narrativas sobre a realidade estudada. E, mesmo em um momento posterior, a interpretação dos desenhos desenvolvidos em campo pela/o própria/o autor/a pode se revelar um material relevante de pesquisa, combinado a fotografias, relatos de campo, gravações e memórias. No fim, talvez possamos dizer que a melhor forma de empregar uma ferramenta de campo é quando ela passa a ser compreendida não como acessório à expressividade, mas sim como parte de um todo que é a produção de sentido que compõe a etnografia.

\section{REFERÊNCIAS}

AGIER, Michel. Do direito à cidade ao fazer-cidade: $\mathrm{O}$ antropólogo, a margem e o centro. Mana, Rio de Janeiro, v. 3, n. 21, p.483-498, jan. 2015.

AZEVEDO, Aina. Um convite à antropologia desenhada. Metagraphias: Metalinguagem e outras figuras, Brasília, v. 1, n. 1, p.194-208, mar. 2016. 
INGOLD, Tim. Repensando o animado, reanimando o pensamento. Espaço Ameríndio, Porto Alegre, v.7, n.2, p. 10-25, jul/dez. 2013.

KUSCHNIR, Karina. A antropologia pelo desenho: Experiências visuais e etnográficas. Cadernos de Arte e Antropologia, v. 5, n. 2, p.5-13, 2016.

PETONNET, Colette. A observação flutuante: o exemplo de um cemitério parisiense. Antropolítica, Niterói, v.1, n.25, p.99-111, 2008.

Recebido: 22/01/2021

Aprovado: 02/06/2021 